\title{
DOKUMENTA
}

NEBOJŠA STAMBOLIJA, istraživač-pripravnik

Institut za savremenu istoriju

Beograd, Trg Nikole Pašića 11

\section{IZVEŠTAJ O STANJU U KOSOVSKOJ MITROVICI I OKOLINI APRILA 1941*}

Jugoslovenska vojska je napad Nemačke 6. aprila 1941. dočekala u fazi opšteg aktiviranja (tajne mobilizacije). U takvom stanju nije bilo moguće izvršiti koncentraciju i strategijski razvoj trupa, pa je do početka rata tek 11 pešadijskih divizija (od ukupno 31), bilo na svojim koncentracijskim prostorima. ${ }^{1}$

Vojni garnizon u Kosovskoj Mitrovici je bio jedan od jačih na području Treće armijske oblasti. Pre rata u njemu je bio smešten 24. pešadijski puk Ibarske divizije, a postojala je i Komanda vojnog okruga koja je bila nadležna za srezove kosovsko-mitrovački, drenički, istočki, pećki, deževski, štavički i rožajski. U K. Mitrovici je još postojalo artiljerijsko skladište i 35. vazduhoplovna baza II reda. ${ }^{2}$

Početak rata je Ibarsku diviziju (koju su uglavnom sačinjavali obveznici sa prostora Kosovske Mitrovice i okoline) zatekao u blizini Skoplja, dok su manji delovi ostali na Kosovu. U samoj Kosovskoj Mitrovici nalazili su se delovi 22. dopunskog puka. ${ }^{3}$ Zbog nesređenog sistema evidencije vojnih obveznika, a i opšteg nepoverenja u albanske mase divizija je ostala nepopunjena. Još 1939, prilikom aktiviranja ratnih jedinica, bilo je predviđeno da se od Nemaca, Mađara i Albanaca formiraju radnički bataljoni, ali ni oni nisu aktivirani aprila 1941. zbog straha da bi mogli obrazovati petu kolonu u pozadini. ${ }^{4}$

U Mitrovici su prva dva dana rata prošla bez naročitih događanja. Već 8. aprila, međutim, kroz grad su počele da se povlače demoralisane tru-

* Rad je deo projekta Srpsko društvo u jugoslovenskoj državi u 20. veku - između demokratije i diktature (br. 177016) koji finansira Ministarstvo prosvete, nauke i tehnološkog razvoja Republike Srbije. 251.

${ }^{1}$ V. Terzić, Slom Kraljevine Jugoslavije. Uzroci i posledice poraza, 2, Beograd 1982,

\footnotetext{
${ }^{2}$ Kosovska Mitrovica i okolina, Kosovska Mitrovica 1979, 247.

${ }^{3} \mathrm{~V}$. Terzić, $n$.d., 256.

${ }^{4}$ Isto, 222.
} 
pe. Nemir i haotično stanje dodatno je pojačavala petokolonaška propaganda koja je govorila o velikim nemačkim uspesima i rasulu jugoslovenske vojske. Najveći deo Ibarske divizije, a sa njom i 24. pešadijski puk bili su razbijeni i zarobljeni drugog dana rata. Oni delovi koji su izbegli zarobljavanje i 4. puk (koji je delom bio smešten u Kosovskoj Mitrovici) upotrebljeni su za zatvaranje pravca od Skoplja ka Kačaniku. Njihov otpor je slomljen 9. aprila, pa su Nemci posle toga zauzeli Uroševac i Štimlje i nastavili nadiranje. ${ }^{5}$

Zbog nepovoljne vojne situacije, Jugoslovenska vrhovna komanda je 8. aprila naredila da se jurišne (četničke) jedinice najhitnije upute u Kosovsku Mitrovicu radi zatvaranja Kačaničke klisure. Ove trupe ipak nisu upotrebljene $\mathrm{u}$ borbi protiv Nemaca već protiv pobunjenog albanskog stanovništva. Komandu nad garnizonom u K. Mitrovici preuzeo je oko 10. aprila general Lazar Tonić, koji nije bio uspešniji u zavođenju reda od svog prethodnika. ${ }^{6}$

Prištinu su 11. aprila osvojili delovi nemačke 9. oklopne divizije i pokušali da se probiju do Kosovske Mitrovice i Peći, ali su zadržani. Da bi se zaustavio dalji nemački prodor preko Kosova, Metohije i Sandžaka u Novom Pazaru je formirana Komanda sandžačke vojske koju su sačinjavali Suvorečki, Pećki, Novopazarski, Kosovsko-mitrovački i Raški odred. Sa novoformiranim snagama 12. aprila pokušan je napad na nemačke snage koje su zauzele Prištinu, ali napad nije uspeo, a odredi su ostali na svojim polaznim položajima. ${ }^{7}$

Nastupajući iz pravca Kraljeva, nemačka 60. motorizovana divizija zauzela je 16. aprila Rašku i, slomivši odbranu Sandžačke vojske, prodrla u Novi Pazar, Sjenicu i Kosovsku Mitrovicu. ${ }^{8}$

Većina albanskog stanovništva iz Kosovske Mitrovice dočekala je Nemce kao oslobodioce izražavajući svoje oduševljenje na brojnim manifestacijama, a gradske ulice su bile iskićene nemačkim zastavama. ${ }^{9}$

O događanjima $u$ gradu za vreme kratkotrajnog Aprilskog rata i neposredno posle i atmosferi linča i neizvesnosti za srpsko stanovništvo, veoma nam je koristan i detaljan izveštaj koji je 13. maja 1941. Komesarskoj upravi u Beogradu podneo Radiša S. Stojković, bivši sreski načelnik u Kosovskoj Mitrovici. Stojković je svoj izveštaj podelio na tri dela, uz još jedan dodatak na kraju.

${ }^{5}$ A. Hadri, Ž. Avramovski, M. Vavić, Okupacioni sistem u Kosovskoj Mitrovici i okolini, Kosovo, 7, Priština 1979, 209-210.

${ }^{6}$ Isto, 211.

${ }^{7}$ V. Terzić, n. d., 387, 402-403.

${ }^{8}$ Isto, 456

${ }_{9}^{9}$ A. Hadri, Ž. Avramovski, M. Vavić, n. d., 212. 
U prvom delu svedoči o događajima neposredno posle dolaska nemačkih trupa i smeni vlasti. Zanimljivo je da Stojković kao dan ulaska nemačkih trupa navodi 17. april, iako se to, po mnogim izvorima, desilo 16. aprila. Pominje se i konferencija koju je sa albanskim prvacima održao komandant nemačke 60. motorizovane divizije. Veoma je detaljno opisana organizacija činovništva i administracije i uloga koju je u prenosu vlasti odigrao Jorgaćije Frtunić, glavni arhivar sreskog načelstva.

Drugi deo izveštaja sadrži podatke o albanskoj pobuni koja je usledila već prvih dana rata i zločinima kojima je bilo izloženo srpsko stanovništvo. U trećem delu je opisana Stojkovićeva lična sudbina i situacija od trenutka odlaska iz mesta službovanja krajem aprila, a u naknadno ubačenom dodatku epizoda sa inicijativom Adema Voce kod nemačkog generala Eberharda da mu se Stojković preda.

Izveštaj se čuva u Vojnom arhivu u Beogradu (fond Nedićeva arhiva, kutija br. 20A, fascikla 1, dokument br. 1, strana 13-16) i do sada nije objavljivan.

Radiša S. Stojković

sreski načelnik

Kos. Mitrovica

\section{MINISTARSTVU UNUTRAŠNJIH POSLOVA}

B E O G R A D

Po naređenju Ministarstva čast mi je podneti izveštaj u pogledu napuštanja mesta službovanja u sledećem.

Mesto službovanja po naređenju nemačkih vojnih vlasti uopšte nisam napuštao. Neprijateljske vojne vlasti sačekao sam u mestu službovanja, te sve po ranijem naređenju naših vojnih vlasti. U prvo vreme, a po naređenju naših vojnih vlasti, arhivu i glavne spise evakuisao sam u selo Banjska poverenog mi sreza, dok svu ostalu arhivu i važnije spise po telefonskom naređenju Kralj. Ban. Uprave Zetske banovine - naređenje lično izdao načelnik upravnog odeljenja g. Vojislav Pekić - spalio sam, te naročito po naređenju sve ono, što bi u sebi imalo kompromitujući karakter. Docnije, dana 16 aprila t. g., kada sam dobio priloženo naređenje vojnih vlasti, po naređenju istih vlasti - telefonskom, kao i po naknadnom telefonskom naređenju iste Banske Uprave, opet u licu načelnika g. Pekića, spaljena je i 
arhiva pripremljena za evakuaciju, sem novčanih dokumenata i knjiga, ličnih podataka, službeničkih listova i ost. arhive a do 1940 god.

Neprijateljske - nemačke trupe ušle se u Kos. Mitrovicu dana 17 aprila t. g. u 6 časova izjutra. Odmah po dolasku istih prijavio sam se istima i dobio naređenje, da ostanem na svome mestu i produžim sa vršenjem službe. Dana 19 aprila t. g. pozvat sam od Komandanta Nemačkih Trupa ${ }^{10}{ }^{10}$ koji je sa svojim štabom otseo u Zvečanu u vili Generalnog Direktora Preduzeća „Trepča“, i prijavio se istom. Odmah za mnom došao je $u$ automobilu nemačke vojske Džafer Deva ${ }^{11}$ industrijalac iz istog mesta i v. d. pretsednika opštine. Bili su dobili odgovor, mene su sa tumačem jednim našim art. kapetanom - Hrvatom po zanimanju inžinjer šumarstva Direkcije Šuma u Sarajevu - ostavili u vili, a g. đeneral sa svojim načelnikom štaba /pukovnikom/ izašao je napolje sa g. Devom, te kako Deva govori perfektno nemački kao đak nemački, zatim turski, arnautski, francuski i engleski, i sa istim ostali u razgovoru oko 2-3 sata. Po ovome Deva je ostao napolje, g. đeneral mi je se obratio i upitao, da li se osećam sigurnim. Na moj odgovor da, te naročito ako budem uživao zaštitu nemačkih vlasti, isti mi je odgovorio, da ću dalje obaveštenje dobiti od g. Deve.

Odmah istog dana g. Deva sa nemačkim vojnim automobilom i jednim oficirom otišao je iz Mitrovice, te po proveri obišao okolne srezove. Sutradan, dana 19 odnosno 20 aprila, po zadatku g. Deva je prikupio iz svih srezova od Prištine do Peći i Sandžaka viđenije Arnaute i u hotelu „Jadran“ održana je zajednička sednica po rukovodstvom g. đenerala nemačke vojske. ${ }^{12}$ Pozitivno sam saznao, da je tada saopšteno i objavljeno, da g. đeneral g. Devu imenuje po ovlašćenju za Okružnog Načelnika za okrug Kosovo, dok za okrug đakovički da je imenovan neki Crnoglavić. Imenovani načelni-

${ }^{10}$ Komandant nemačkih trupa u ovom trenutku u Kosovskoj Mitrovici bio je general-potpukovnik Georg Fridrih Eberhard, komandant 60. motorizovane pešadijske divizije (A. Hadri, Ž. Avramovski, M. Vavić, n. d., 235).

${ }^{11}$ Industrijalac iz Kosovske Mitrovice, jedan od najistaknutijih nemačkih saradnika na Kosovu. Jedan je od osnivača Druge prizrenske lige i 21. SS divizije Skenderbeg. Od kraja 1943. do sredine 1944. bio je i ministar unutrašnjih poslova u albanskoj vladi pod pokroviteljstvom Nemaca. Umro u emigraciji (A. Hadri, Ž. Avramovski, M. Vavić, n. d., 212).

${ }^{12} \mathrm{Na}$ sastanku održanom 21. aprila prisustvovali su sa nemačke strane komandant 60. motorizovane divizije general Eberhard sa svojim oficirima, a albansku je predvodio Džafer Deva koji je bio i predstavnik Kosovske Mitrovice. U albanskoj delegaciji bili su prisutni i predstavnici Sjenice, Novog Pazara, Vučitrna, Prištine, Podujeva, Drenice, Istoka i Peći. Na sastanku je dogovoreno da vlast u pomenutim mestima preuzmu Albanci, da se organizuje albanska pomoćna milicija, da se počne sa „evakuacijom“ kolonizovanih Srba, kao i uređenje finansijske i sudske vlasti. Sporazum u ovom obliku nije zaživeo zbog italijansko-nemačkih dogovora o podeli zona. Detaljnije o ovome: A. Hadri, Narodnooslobodilački pokret na Kosovu 1941-1945, Beograd 1973, 119-121; S. Milošević, Saradnici nemačkog okupatora na Kosovu 1941-1944, Kosovo, 7, Priština 1978, 184-185. 
ci dobili su pravo celokupne uprave, postavljenja sr. načelnika, činovništva svih struka i. t.d. U okrug Kosovski sa sedištem u K. Mitrovici spali su sledeći srezovi: Gračanički, labski, vučitrnski, k. mitrovački, drenički, istočki, pećski, štavički, deževski i dr. srezovi sandžaka. Okrug Đakovica: Đakovica, Prizren, Orahovac, Suva Reka, Dragaš, Uroševac, srezovi oko Debra i dva sreza Albanije, te koliko se sada sećam i znam srez u Kukusu i jedan obližnji srez.

Žandarmerija je razoružana i odvedena u logor vojnika dana 21 aprila 1941 god.

Nemačka Komanda Mesta uselila je se u sresko načelstvo dana 19 aprila t. g. i zauzete sve naše kancelarije. Mi nismo ništa radili niti nam je se dozvoljavalo, već po naređenju imali smo svaki dan dolaziti i sedeli smo u dvorištu sreza od 8-12 i od 15-18 časova. Protivno postupanje snosilo bi posledicu, da nam se ne bi jamčilo za živote i ne bi imali zaštite. Za to vreme pak nosili smo na levom rukavu ruke na beloj traci ispisana zvanja na nemačkom jeziku.

Dana 28 aprila t. g. došao je u načelstvo FRTUNIĆ JORGAĆIJE glavni arhivar poverenog mi načelstva, pozvao potpisatoga i službenike i saopštio nam, da je došao, da mu po naređenju Okr. Načelnika predamo srez i sresko načelstvo. Odbio sam i tražio na uvid pismeno naređenje, koje mi je pokazao, ali mi nije hteo isto dati niti u prostom niti overenom prepisu. Naređenje je pisano na četvrt tabaka hartije pisaćom mašinom i na nemačkom jeziku. Nosilo je u mesto pečata mašinom ispisano "Okružno načelstvo u Kos. Mitrovici, dana 26 aprila 1941. br. 3/41". Naređenje je potpisano od imenovanog Okr. Načelnika g. Džafera Deve i upućeno na ime Frtuniću sa naređenjem, da smesta ode u sresko načelstvo, isto sa kancelarijama, inventarom i dr. primi, kao i gotov novac, a zatim da čeka dalje naređenje. Nisam se mogao u ovakvoj situaciji odupreti, te sam zapisnički Frtuniću predao srez kao i dinara 13.331,63 koliko je se depozita u kasi načelstva zateklo. Tražio sam, da se zapisnik sačini u 3 primerka, kako bih jedan dobio, ali sam odbijen od Frtunića „da je nepotrebno i da zato nema naređenje" te je isti sačinjen u 2 primerka. Isti sam potpisao kao i činovnici: podnačelnik Andrija Ivanov, pisari: Matić Slavko, Jovičić Aleksandar, Radifković Risto /banovinski činovnik VIII gr./ inž. šumarstva referent Soljanik Ivan, te zvaničnik Racić Isidor. Po ovome Frtunić je zatvorio srez i otišao Okr. Načelniku a nama saopštio da smo slobodni. Našavši se u takvoj situaciji, raspustio sam činovnike, odn. saopštio im, da idu svojim kućama, te smo se obratili za objave koje nam je okr. načelnik izdao /pisane na nemačkom i albanskom jeziku sa okr. pečatom na istim jezicima i hokenkrojcem/. 
Mesto službovanja morao sam napustiti, kako sa iznetih razloga jer sam razrešen, tako i razloga, što mi je pretila pogibelj ubistva, jer su u varoš sišli Arnauti te gotovo svi oglašeni odmetnici-kačaci, koji su došli iz Albanije, te koji su specijalno potpisatoga tražili i dano noćno jurili da ga ubiju, radi čega je potpisati morao se kriti po tuđim kućama, menjajući i preko dana i preko noći kuće i stanovanje.

Napuštanjem mesta službovanja a i ranije, razgrabljena mi je i totalno upropašćena cela kuća sa pokućanstvom tako, da sam pobegao samo sa jednim starim odelom na sebi i iznošenim cipelama. Ostalo propalo i ostalo da propadne. Isto tako i porodica mi je pobegla ranije, no i ona nije ništa odnela sobom, već izvukla samo golu dušu. Ovo sa razloga, jer od momenta kada su nemačke trupe probile naš front kod Krive Palanke, nastupila je arnautska pobuna, koja je iz dana u dan sve više besnela i sve većeg maha i sve većih srazmera uzimala. Prividno, ali veoma malo, stanje pobune popustilo je, kada je od naših vojnika ubijen Šerif Voca ${ }^{13}$ rodom iz Šalje istoimene opštine sreza vučitrnskog, stalno živeći u K. Mitrovici i biv. narodni poslanik, koji je od našeg Ministarstva preko poverenog mi načelstva primao stalnu pomoć u dinara 2500 mesečno. Isti je ubijen po podne oko 15 časova kada je počeo bežati iz K. Mitrovice. Ubijen je u mestu zvanom „Ajrulova njiva“" odmah u blizini mitrovačkog pravoslavnog groblja, atara opštine zvečanske a sela Šupkovac. Bio je u ženskom odelu muslimanskom - bule, te po provedenom izviđaju vojska je mislila da ima pred sobom špijuna. Osim toga, što nije hteo stati na nekoliko poziva vojske, te je na njega pripucano i isti ubijen.

2/. Napred sam naveo momenat početka arnautske pobune. Ista je uzimala sve većeg maha, te po proceni pobunjenika je bilo nekoliko hiljada, među kojima i naših vojnika Arnauta koji su sa oružjem pobegli iz svojih trupa i pristupili pobunjenicima. Pobunjenika je najviše bilo u dreničkom, vučitrnskom, k. mitrovačkom, pećskom, gnjilanskom u gračaničkom srezu, te između ostalog svima srezovima Kosova. Usled napuštanja Prištine od strane Kom. Kos. Diviz. Oblasti, te što isti nije uništio magacine već ostavio nedirnute, tragedija je, da su Arnauti došli ne samo do municije, no do pušaka, puško-mitroljeza, mitroljeza i bombi tako, da su pobuna i arnautski napadi imali karakter jedne dobre organizacije i jednog formalnog rata.

Pobunjenici su presretali i ubijali naše vojnike i građane, koji su dolazili od Skoplja ka Mitrovici tako, da su od Mitrovice pa ka tim mestima ležali i ostajali leševi naših vojnika i građana. Svi su opljačkani. Po ovome

${ }^{13}$ Predsednik opštine u Šalji i bivši narodni poslanik koji je 1938. izabran na listi Jugoslovenske radikalne zajednice. Zbog govora u skupštini protiv iseljavanja Albanaca u Tursku bio je emigrirao iz Jugoslavije 1938. da bi se vratio 1940. godine (A. Hadri, Ž. Avramovski, M. Vavić, n. d., 212). 
napali su žandarmerijske stanice i sa istima formalne ratove vodili, da je veliki broj naših žandarma izginulo i nekoliko oficira. Žalosna je pojava, da kada smo tražili pomoć od Komandanta Mitrovačkog Odreda, đenerala Lazara Tonića, ${ }^{14}$ da isti pomoć nije hteo dati, sa motivacijom, da ne može dati jedinice sa fronta, te dao jednu polučetu 4 puka i sa njima, te starcima streljačkih četa održavan je nekako red i sprečen napad i ulaz istih u K. Mitrovicu. Docnije, kada je objavljeno primirje, kada vojska više nije trebala, kada u stvari front nije postojao, takođe pomoć nismo dobili premda mu je sve to predočeno tako, da smo ostali samo na milost i nemilost i borili se sa žandarmima evakuisane prištinske i dr. žand. četa. Vrhunac pobune je bio dana 16-20 aprila. Tražena je pomoć od nemačkih vlasti ili pak da povrate oružje žandarmeriji. Odbijeni smo sa rečima "Mi nismo hteli rat, sami se pomažite!" Tek docnije, dana 22 aprila, kada su Arnauti ubili i neke nemačke vojnike, nemačke trupe su sa manjim odredom otišle u Drenicu i dr. mesta te je pobuna počela popuštati.

Arnauti pobunjenici rasturili su sav naš živalj, te koga nisu stigli ubiti, naredili su da napuste mesta sa rokovima od jednog do 3 sata. Tako je postupljano i postupljeno i prema kolonistima, koji su takođe mnogo stradali, desetkovani i poubijani tako, da su isti ostavili svu imovinu i sa decom i porodicama pobegli goli i bosi spasavajući samo goli život. Još do dolaska neprijatelja, Arnauti su poubijali mnogo naših vojnika i ljudi, te žena i dece. Posle ovoga, dolaskom nemačkih trupa isto, te u poslednje vreme, što i danas po proveri i saznaju čine, upadaju u domove našeg življa, odvode ih, te ili batinaju ili se masa istih uopšte više ne vrati. Na ovaj način masa naših ljudi nestalo je. Ovo naročito oni koji su došli posle 1918 god., tako se postupa i prema nekim domorodcima. U Vučitrnu bila su dva silovanja naših mladoletnih devojaka.

Sreski načelnik od Arnauta je organizovao žandarmeriju. Odnosno Okr. Načelnik Deva, koja nosi našu uniformu samo na glavama keče. Postavio je mesnu policiju te na čelu iste je Osman Solid trgovac, koji se naročito ističe u svome besu prema Srbima. Od biv. arnauta opšt. policajaca, žandara katolika /Hrvata i Slovenaca/ postavio je po našim stanicama komandire stanica. Zatim je izmenio opšt. Upravu i imenovao:

U Kos. Mitrovici za pretsednika Šabana Mustafu dosadanjeg potpretsednika a za potpretsednike Mustafu Devu trgovca i Viktora Akšiju knjižara. U Zvečanskoj opštini smenio Srbina pretsednika i postavio za

${ }^{14}$ Divizijski general, rođen 1884. u Orahovcu kod Prizrena. U Aprilskom ratu najpre komandant Moravske divizije pa Kosovsko-mitrovačkog odreda. Odveden u zarobljeništvo, odakle je pušten 17. septembra 1941, ali je ponovo vraćen 17. februara 1942. jer nije hteo da prihvati saradnju sa Nemcima. Posle rata ostao u emigraciji gde je i umro 1975. Videti: M. S. Bjelajac, Generali i admirali Kraljevine Jugoslavije 1918-1941, Beograd 2004, 293. 
pretsednika Musu Boljetinca a za delovođu Šabana Idriza dotadanjeg pretsednika opštine žabarske. U Žabarima imenovao za pretsednika Šabana Redžu biv. ranijeg pretsednika. Za ovim izmenio je i u ostalim srpskim opštinama. Sve smene izvršio je na licu mesta Frtunić Jorgaćije biv. arhivar glavni sreza, kojega je zadržao u Okr. načelstvu kod njega na radu, te isti ili je šef njegova kabineta ili pak pomoćni organ u sreskom načelstvu. Po proveri kod novo došavši i pobeglih građana i činovnika, rad i postupak Frtunića osuđuje se i prati sa gnušanjem, te u koliko je ovo tačno sve, nemogu tvrditi niti optužbe protivu istog podnositi sem što sam saznao i preživeo. Pisar moga načelstva g. Jovičić Aleksandar doputovao je ovde dana 11 t. m. i rekao mi, da mu je Frtunić rekao, da je za njega bolje da se izgubi iz Mitrovice. Da mu je tražio napismeno, opsovao ga, ali da mu ovaj nije ništa dao, već samo gornje rekao.

Okr. načelnik razrešio je i sve poštanske službenike, te poštu poverio Šukriji Sulejmanoviću pošt. činovniku /viši pošt. kontrolor VI gr./ Saopšteno je, da u službi može ostati samo odan i onaj ko zna albanski jezik i pravopis.

Razrešio je i poreske činovnike. Za šefa uprave postavio je Dušana Ćirića biv. por. činovnika, meštanina, koji je po čuvenju odgovarao kod suda te dali je osuđen ili ne, zašto je odgovarao i da li je otpušten ili penzionisan, nemam podataka niti ma šta dr. o istome mogu reći.

Pre razrešenja Okr. Načelnik je sa jednim nemačkim oficirom došao i uzeo sav gotov novac iz Poreske Uprave, te po saznanju nešto preko 200.000 dinara.

Okr. načelnik Deva do dolaska neprijatelja, dokle je vršio dužnost pretsednika bio je vrlo dobar, te dosta pomagao na suzbijanju pobune i zaštiti reda i življa. U prvo vreme dolaska nemačkih trupa isto. Znam pozitivno, da je na moju molbu spasao od smrti žand. narednika u penziji Metikoša, kod koga je pretresom pronađeno 2 bombe.

U službu Arnautima i nemačkim vlastima mnogo su se istakli i ističu se: Viktor Mihelčić suspendovani zamenik državnog tužioca i Požarnik sanitetski narednik vodnik, koji je - ovaj poslednji - optužio nemačkim vlastima naš kvart Srba preko Ibra oko kafane „London“ da imaju skrivenog oružja, te je pretres vršen i kod rečenog Metikoša tada i nađene bombe.

Arslan Boljetinac student, koji je primao pomoć kao i brat mu Baja$z^{15}{ }^{15}$ naš rez. konj. kapetan i majka im preko mog načelstva, $u$ mnogome je

${ }^{15}$ Bajazit Boljetinac, penzionisani kapetan jugoslovenske vojske, sin poznatog odmetnika Ise Boljetinca. Dolaskom Nemaca postaje komandant „albanske žandarmerije“ na prostoru Kosovske Mitrovice, Podujeva, Vučitrna i Novog Pazara. Isticao se kao pristalica prisajedinjenja Kosovske Mitrovice i okoline Albaniji. Posle reorganizacije srpskog kolaboracionističkog sistema bezbednosti, sredinom 1942, postaje komandant Okružne komande 
se istakao, te na manifestacijama držao govor slaveći oslobođenje posle 30 godišnje robovanja pod Srbima. Do dolaska italijanskih trupa u Drenicu, bio je imenovani sreski načelnik $u$ istom srezu.

Po ličnoj uveri i prikupljenim podacima proverom, nemože se naći ni jedan Arnautin naklonjen nama, te je sada po prikupljenim podacima sve teže i očajnije stanje našeg življa tako, da iz dana u dan isto vapi, traži pomoć i zaštitu a službenici i pojedini građani beže u Srbiju i za Beograd. Naročito zbog sada uvedenog sistema, da noću odvode građane, od kojih retko se koji vraća te se nezna šta je sa istima.

Srez po popisu iz 1931 god. ima svega 38\% muslimana. Od 8 opština stanje sledeće: Mitrovačka većina muslimani, žabarska isto, zvečanska pola i pola, slatinska muslimana jedva 20\%, leposavićska, radičpoljska, banjska i berimska stoprocentno srpske sa srpskim življem.

3/. Iz Mitrovice pobegao sam u Čačak i otseo kod Slobodana Vilotijevića zubara, koji je brat od ujaka moje žene, te kod kojega se nalazi moja žena i dvoje dece i to: sin đak V i ćerka đak II razreda gimnazije. Na drugo mesto nisam mogao otići, jer nam je cela kuća propala, te nas je on privremeno prihvatio i dao nam utočišta. U Beograd sam došao odmah čim sam saznao za imenovanje Saveta Komesara t. j. dana 3 maja t. g. i odmah istog dana prijavio se Ministarstvu i upisao se u spisak prijavljenih činovnika i službenika. Dakle, od dana 29 aprila kada sam napustio mesto službovanja pa do 3 maja t. g. proveo sam u Čačku kod brata od ujaka svoje žene, napred navedenog, pošto mi je cela imovina propala, te nisam imao gde otsesti sa porodicom.

S obzirom na napred izloženo, a naročito da mi je imovina sa pokućanstvom propala, nemam uslova niti mogućnosti službovati niti ma gde živeti do jedino u Čačku, jer nemam mogućnosti nabavljati dr. pokućanstvo, molim Ministarstvo da ovu okolnost ima u vidu prilikom rasporeda, te da budem raspoređen u Čačku ili tamo u to mesto postavljen.

Srpske državne straže. Po kapitulaciji Italije postavljen je za komandanta „Kosovskog puka“, sa kojim vrši mnogobrojne zločine nad Srbima na prostoru Peći i Prizrena. Bio je oficir sa činom potpukovnika u 21. SS diviziji „Skenderbeg“. Povukao se sa Nemcima u Austriju 1944, umro u emigraciji (A. Hadri, NOP na Kosovu 1941-1945, 118-119, 303; S. C. Ćirković, Ko je ko u Nedićevoj Srbiji 1941-1944, Beograd 2009, 74-75). 
Prednji izveštaj s molbom na znanje i nadležnost.

U Beogradu dana 13 maja 1941 god.

Učtiv, Rad. Stojković, s. r.

sreski načelnik iz Kos. Mitrovice sada na stanu privremeno kod Julije Mirković penzionera

Beograd Kosmajska ulica br. 38

u Čačku na stanu kod Slobodana

Vilotijevića zubara, Pašićeva ul.

Dodatak:

Dana 22 aprila t. g. bio sam prisutan, kada je u sr. načelstvo, odn. Komandu Mesta došao Adem Voca brat poginulog Šerifa sa Šerifovim sinom Eminom, jednim muslimanom po imenu Jonuz iz Gusinja radenik Trepče, kojega lično poznajem te Viktorom Mihelčićem suspendovanim zamenikom Drž. Tužioca. Tražili su prijem kod Komandanta te da tumač bude rečeni Mihelčić, pošto ima da saopšti izvesne stvari koje se tiču Srba. Međutim tumač je bio poručnik IV peš. puka /rezervni/ Lazić rodom iz Srbobrana, po zanimanju inž. agronomije i polj. referent sr. načelstva u V. Kikindi. Koma[n]dan[t] mesta kapetan odbio je i saopštio, da on ima poverenje u svoga tumača, a da Mihelčić ide jer je inače pijan. Tada sam čuo iz susedne služ. sobe, koja je pregrađena ofarbanim daskama a potom docnije pričao mi je i tumač Lazić da je cilj dolaska bio: da traže od nemačkih vlasti nagradu zbog pogibije Šerifove, da je isti radio sa nemačkim konzulom u Skoplju, te da je arnautska pobuna njegovo delo. Potom, da je ubijeni Šerif kod sebe imao 120 napoleona, dok mu je podnačelnik dao svega nađenih 368 dinara, te da traži povraćaj novca. Zatim, da se njima Arnautima predaju potpisati sreski načelnik i Komandant Mesta pukovnik Vojislav Kaličanin na suđenje, u protivnom da se istima sudi od nem. voj. vlasti. Komandant Mesta odgovorio je, što sam lično i preko tumača čuo: da su oni prodorne trupe, te ako ima šta, neka ide njihovom konzulu u Skoplje, uzme podatke i donese pa će ih predati g. Đeneralu. Da je isti poginuo 14 a oni došli 17 aprila, te da sa tih razloga ne može predati sr. načelnika i Komandanta Mesta, a oni ako imaju šta, neka se obrate sudu. Na taj način dobili smo zaštitu i spašeni, no posle toga od Šerifove braće, sinova i ljudi traženi i jureni da budemo ubijeni.

U petak dana 25 aprila t. g. takođe sam bio prisutan i video, da je Šerifov brat doneo neko pismeno od nemačkog konzula i predao sa nekim pismenim aktom Komandi Mesta, te sam od tumača obavešten, da je po sredi postupak po gornjem uputu i da je isti doneo gornje dokaze. Šta je dalje bilo neznam. 
Ova stvar jasan dokaz pruža, da je arnautska pobuna stvarno i delo ubijenog Šerifa Voce, kao i ostalih prvaka, te da su po sredi istinite priče, da je isti preobučen u žensko odelo pokušao pobeći u selo, da bi akcijom pobune lakše rukovodio, a izgovor da je bežao plašeći se Komandanta Mesta, koji ga je zvao na razgovor, da bi ga činio odgovornim za pobunu i zahtevao da se ista spreči, samo je priča gola u vremenu postojanja naših vlasti. Prednje se može proveriti i preko gore navedenog rez. poručnika Lazića.

Rad. Stojković, s. r. sreski načelnik 